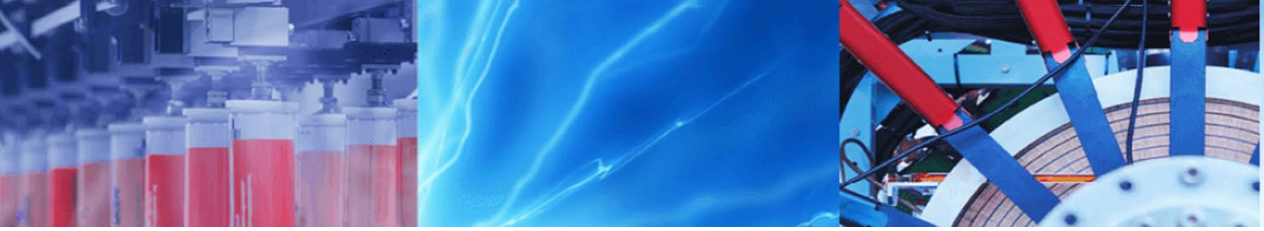

Research Article

\title{
Influence of laminate direction and glue area on in-plane shear modulus of cross-laminated timber
}

\author{
Jonas Turesson ${ }^{1}\left[\right.$ Zahra Sharifi $^{1}\left[\right.$ D $\cdot$ Sven Berg ${ }^{1} \cdot$ Mats Ekevad $^{1}$
}

Received: 16 August 2020 / Accepted: 18 November 2020 / Published online: 1 December 2020

(c) The Author(s) 2020 OPEN

\begin{abstract}
The use of cross-laminated timber (CLT) in constructing tall buildings has increased. So, it has become crucial to get a higher in-plane stiffness in CLT panels. One way of increasing the shear modulus, $G$, for CLT panels can be by alternating the layers to other angles than the traditional $0^{\circ}$ and $90^{\circ}$. The diagonal compression test can be used to measure the shear stiffness from which $G$ is calculated. A general equation for calculating the $G$ value for the CLT panels tested in the diagonal compression test was established and verified by tests, finite element simulations and external data. The equation was created from finite element simulations of full-scale CLT walls. By this equation, the influence on the $G$ value was a factor of 2.8 and 2.0 by alternating the main laminate direction of the mid layer from the traditional $90^{\circ}$ to $45^{\circ}$ and $30^{\circ}$, respectively. From practical tests, these increases were measured to 2.9 and 1.8 , respectively. Another influence on the $G$ value was studied by the reduction of the glue area between the layers. It was shown that the pattern of the contact area was more important than the size of the contact area.
\end{abstract}

Keywords Cross-laminated timber · Diagonal compression test · Laminate direction · Shear modulus · Finite elements . Glue

\section{Introduction}

A cross-laminated timber (CLT) panel is a building component used for a variety of purposes such as walls, floors, roofs and beams [1]. CLT is a panel built by boards in a cross wise arrangement in a specific number of layers. Normally an odd number of layers 3,5 and 7 is used, but also CLT with an even number of layers 2, 4 and 6 is possible. Boards used to construct CLT panels are based on strength class and dimension. The material and size of the boards will determine the properties of the CLT panel [2]. One important property of the CLT panels is the inplane shear stiffness characterised by the shear modulus, $G$. This is not interchangeable with the shear modulus of wood because shearing of a CLT panel does not necessarily mean shearing of the wood. $G$ is important for CLT walls if they are used as shear walls to resist lateral movements of buildings. Lateral (shear) stiffness is important, and it is necessary to have sufficient lateral stiffness, especially for tall wooden buildings [3]. Several parameters affect the shear stiffness in a CLT panel. Important parameters are constituent board dimensions, board strength class, possible gaps between boards, gluing method and gluing area and the number of layers that build the CLT panel [4]. Traditional CLT panels use cross wise laminate directions, meaning directions $0^{\circ}, 90^{\circ}, 0^{\circ}$ and so on as directions of the laminates. Two possible gluing methods are used for CLT panels. One is to glue only the flat sides of the boards, and the other one is to glue both flat and side edges. For the CLT panels glued on both flat and side edges of the boards, $G$ will be equal to the shear modulus of solid wood [5]. Omitting side edge gluing means that $G$ will be lower

$\triangle$ Jonas Turesson, jonas.turesson@ltu.se| 'Department of Engineering Sciences and Mathematics, Division of Wood Science and Engineering, Skellefteå Campus, Luleå University of Technology, Forskargatan 1, 93177 Skellefteå, Sweden. 
than the shear modulus for solid wood. Using main laminate directions different from $90^{\circ}$ in the mid layer is an interesting possibility to increase $G$, and that is the focus of this study.

The effect of the board dimensions on $G$ for 3 - and 5 -layer panels has been studied earlier by Turesson et al. [4]. Other studies have concluded that board dimensions affect $G$ but not analysed how much. Some studies have calculated $G$ from different variants of the picture frame testing method; see [6-9], and others have used the diagonal compression test method $[5,6,10,11]$. Recently, a method similar to the diagonal compression test has been used, but in a more sophisticated way $[12,13]$. In the study by Bosl [7], 5-layer panels with the mid layer arranged at $45^{\circ}$ have been analysed, both in theory and practice. In this study, a doubled $G$ was presented by changing the main laminate direction of the mid layer from $0^{\circ}$ to $45^{\circ}$. This is the only study found where the influence on $G$ by an alternative main laminate direction has been tested.

The diagonal compression test method, which is analysed in this study, contends to define the shear stress occurring in the diagonally compressed sample. To calculate the shear stress in a diagonally compressed CLT panel, an isotropic model without any layers and gaps between boards has been used $[6,11]$. In [6], this was the reason for the less accurate result from the diagonal compression test. The isotropic shear stress has been adjusted in [5] where the equation for calculating $G$ was created based on FE (finite element) simulations. The limited scope in [5] 0 resulted in a restricted equation which is only valid for the specific sizes and conditions occurring in the study and not in a general case. In [10], an equation suitable for a perfect shear condition has been used, but this situation does not occur during a diagonal compression test [6]. This method of assuming a perfect shear condition has been used earlier for other orthotropic materials like masonry [14], but the conditions for CLT panels are not equivalent.

The diagonal compression test is a relatively simple method which can be used to measure shear stiffnesses of CLT panels. However, there is a need for a suitable equation to calculate $G$ from the measured stiffnesses where the size of the CLT panels and the measured areas are arbitrary.

The aim of this study is twofold: first, to conduct FE simulations and tests to develop an equation for calculating $G$ by diagonal compression test for CLT panels, and second, to use this equation to calculate $G$ for non-edge glued 3-layer CLT panels with varying main laminate directions in order to maximise $G$. Also, to show the effect on $G$ by reduction of the glued areas in CLT panels. No earlier study has shown this effect.

\section{Method}

Three variants of CLT panels with different main laminate directions were the basis for the study. Layers one, three and five were called the odd layers, and layers two and four were called the even layers. Layers two and three were called the mid layer for the 3- and 5-layer CLT panels, respectively. The main laminate direction of a layer was the direction of the wooden fibres of the boards that built the layer. All CLT panels were non-edge glued. CLT panels with a cross wise board layup were called "ordinary", and CLT panels with the main laminate direction of $30^{\circ}$ and $45^{\circ}$ for the mid layer were called "non-ordinary"; see Table 1. Gaps between neighbouring board edges ("Gp") were used to assure non-edge glued panels. Each panel was named according to the main laminate direction of the mid layer. Panels 3L30Gp, 3L45Gp and 3L90Gp had board dimensions representing a $1 / 2$ scaled version of a commercially used CLT panel. These CLT panels were used in the diagonal compression test and FE simulations. A full-scale CLT panel named 3L90 was also created and analysed in FE simulations. This CLT panel had dimensions twice as large as the $1 / 2$ scaled CLT panels. Two additional CLT panels denoted $3 \mathrm{~L} 90 \mathrm{M}$ and $5 \mathrm{LOM}$, where " $\mathrm{M}$ " means manufactured, were used in the practical test and FE analysis for confirmation of the results.

The 3L30Gp, 3L45Gp and 3L90Gp CLT panels had controlled board positions. This means that the boards were arranged symmetrically around the midpoint of all layers,

Table 1 Analysed CLT panels

\begin{tabular}{|c|c|c|c|c|c|}
\hline Name & No. of layers & Main laminate directions & $\begin{array}{l}\text { Gap between side } \\
\text { edges }[\mathrm{mm}]\end{array}$ & $w_{\text {board }} \times t_{\text {board }}[\mathrm{mm}]$ & Panel size $L_{T} \times L_{T} \times t[\mathrm{~mm}]$ \\
\hline 3L30Gp & 3 & $0^{\circ} / 30^{\circ} / 0^{\circ}$ & 1 & $75 \times 15$ & $600 \times 600 \times 45$ \\
\hline $3 L 45 G p$ & $"$ & $0^{\circ} / 45^{\circ} / 0^{\circ}$ & $"$ & $"$ & $"$ \\
\hline 3L90Gp & $"$ & $0^{\circ} / 90^{\circ} / 0^{\circ}$ & $"$ & $"$ & $"$ \\
\hline 3L90 & $"$ & $"$ & 0 & $150 \times 30$ & $1200 \times 1200 \times 90$ \\
\hline 3L90M & $"$ & $"$ & $"$ & $190 \times 40$ & $1200 \times 1200 \times 120$ \\
\hline 5LOM & 5 & $0^{\circ} / 90^{\circ} / 0^{\circ} / 90^{\circ} / 0^{\circ}$ & $"$ & $220 \times 46$ & $700 \times 700 \times 230$ \\
\hline
\end{tabular}


as shown for the mid layers in Fig. 1a-c. The boards in the odd layers were arranged with the main laminate direction at $0^{\circ}$, as shown in Fig. $1 \mathrm{~d}$. The 3L90, 3L90M and 5LOM CLT panels were created without controlled board position.

\subsection{Diagonal compression test}

In the diagonal compression test method, a square CLT panel was compressed in one diagonal direction by a displacement controlled hydraulic jack. Please refer to $[5,6]$ for more details on the test procedure.

During a diagonal compression test, only one diagonal was compressed, and the second diagonal was left without control of the displacement. This created an uneven deformation of the sample and gave two different load versus displacement relations, one for each diagonal. There were two choices for the loading direction since all square CLT panels had two equal diagonals. For the ordinary CLT panels where the board lay-up was cross wise directed (e.g. $0^{\circ}, 90^{\circ}$ and $0^{\circ}$ ), the two choices of loading direction were arbitrary, as shown in Fig. 2a. This means that the shear stiffness of an ordinary CLT panel did not depend on the choice of the compressed diagonal. However, this was not the case for non-ordinary CLT panels, as shown in Fig. $2 b$ and c. Testing on one of the diagonals for 3L30Gp or 3L45Gp would result in a compression similar to the ordinary CLT panel i.e. in somewhat "cross-fibre" direction, cf. Figure $2 \mathrm{~b}$ for CLT panel 3L45Gp. The situation changed in the case of compressing the other diagonal, where the compression in the mid layer would be in somewhat "fibre" direction, cf. Figure 2c for CLT panel 3L30Gp. So, in the testing of $3 \mathrm{~L} 30 \mathrm{Gp}$ and $3 \mathrm{~L} 45 \mathrm{Gp}$, both the fibre and the cross-fibre directions were tested.

The two supports illustrated in Fig. 2a-c. had the same dimensions. The contact length between one side of the support and the thickness side of the CLT panel was $110 \mathrm{~mm}$ out of the total support length, $L_{S}, 130 \mathrm{~mm}$ due to the cut off corner, as shown in Fig. $2 a-c$. The length

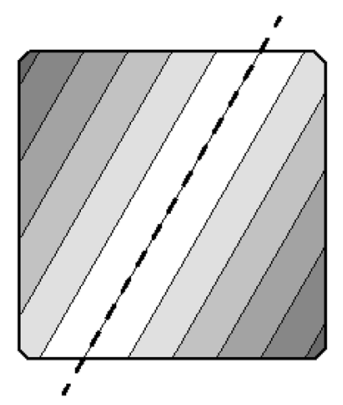

(a)

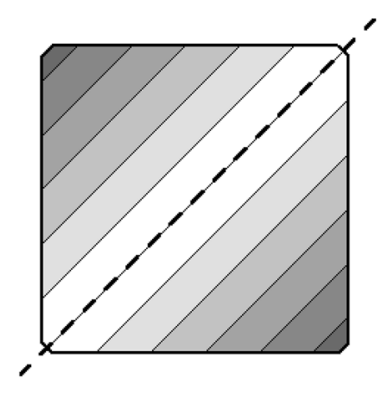

(b)

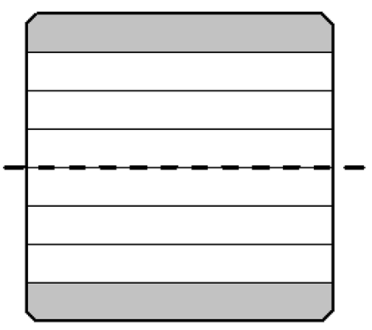

(c)

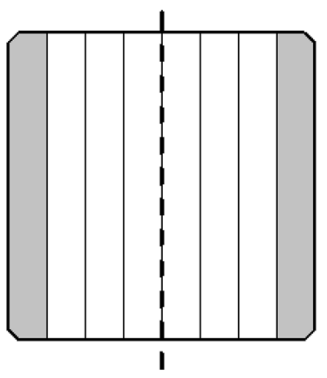

(d)

Fig. 1 Board positions for the mid and odd layers of 3L30Gp, 3L45Gp and 3L90Gp CLT panels. The non-ordinary CLT panels with the main laminate direction of the mid layer at $30^{\circ}$ and $45^{\circ}$ are presented in (a) and (b), respectively. The ordinary CLT panel with the

main laminate direction of the mid layer at $90^{\circ}$ is shown in (c). The odd layers with the main laminate direction at $0^{\circ}$ are shown in (d). The dashed line illustrates the symmetry axis, and the colours indicate the boards with equal dimensions in each panel

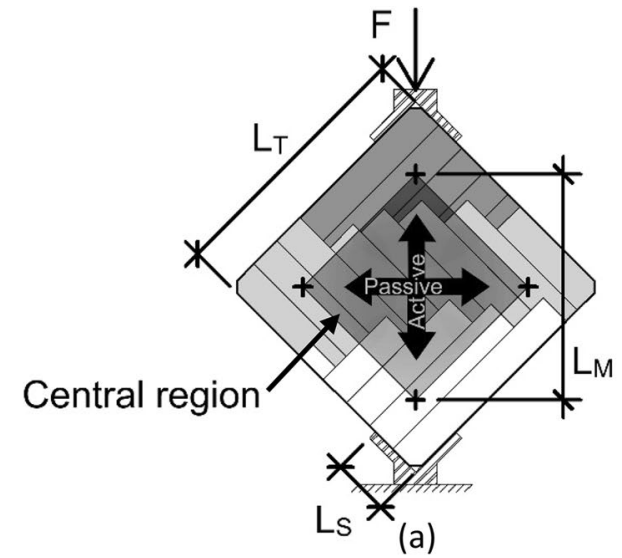

Fig. 2 An ordinary CLT panel compressed in the direction named cross-fibre (a), a non-ordinary CLT panel compressed in the direction named cross-fibre (b), and a non-ordinary CLT panel com-

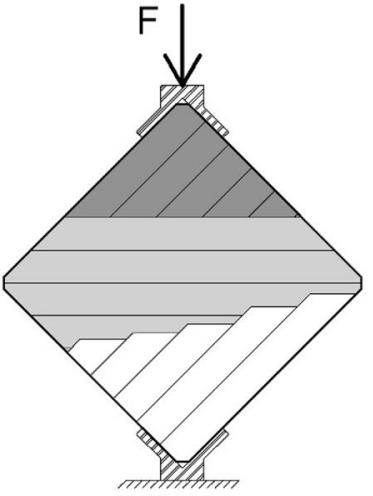

(b)

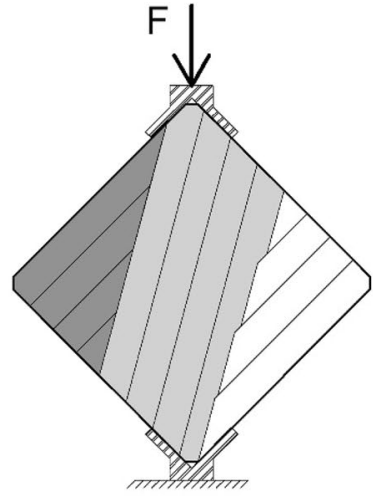

(c) pressed in the direction named fibre (c). Grey scale shows the main laminate directions and the central region where the displacements were measured 
between the measuring points was denoted $L_{M}$, and the side length of the CLT panel was denoted $L_{T}$. Relative linear displacements were measured along the two diagonals as described earlier in [6]. The displacements were always seen as positive values independent of compression or extension. The displacements in the force direction and the perpendicular-to-force direction, $\Delta_{\text {active }}$ and $\Delta_{\text {passive }}$ respectively, were the changes of $L_{M}$, as shown in Fig. 2a. In [6], the square area defined by the measuring points was called the central region of the CLT panel, as shown in Fig. 2a. The size of the central region was described by the ratio between the area representing the central region and the total area of the panel. In $[5,6,11]$, the central region was $16 \%$. A central region of $37 \%$ was used in this paper for $3 \mathrm{~L} 30 \mathrm{Gp}, 3 \mathrm{~L} 45 \mathrm{Gp}$, 3L90Gp and $3 \mathrm{~L} 90$ variants and $66 \%$ and $45 \%$ for $3 \mathrm{~L} 90 \mathrm{M}$ and $5 \mathrm{LOM}$, respectively.

\subsection{Finite element analysis}

The CLT panels were built in FE models by adding multiple boards with dimensions shown in Table 1 . To be able to fit the CLT panels in the diagonal compression test setup, the length of $20 \mathrm{~mm}$ of the corners was removed, as shown in Fig. 2.

Material data for wood were obtained from the Swedish standard for the material classification [15] and defined by ratios between moduli in different directions and the longitudinal (fibre) direction. A mean value for longitudinal elastic modulus, $E_{l}$, was used for all orthotropic models in this paper. It was obtained from four-point flexural tests on cut-out samples from the CLT panels used in the diagonal compression test. The ratios of the radial modulus of elasticity $E_{r} / E_{l}$, the shear modulus $G_{l r} / E_{l}$ and the rolling shear modulus $G_{r t} / G_{l r}$ were $0.0336,0.0627$ and 0.10 , respectively. The tangential modulus of elasticity, $E_{t}$, and the shear modulus $G_{l t}$ were equal to $E_{r}$ and $G_{l r}$ respectively. Poisson's ratios were set to zero due to the recommendation in the Swedish standard [16]. To reduce the calculation time, a symmetry condition was used in the thickness direction of the CLT panels.

A contact condition was applied on all glued surfaces. Slip, separation and penetration between surfaces in contact were prohibited for all glued surfaces. Glued surfaces were assumed full or reduced. Reduced contact surfaces in 3 L30Gp, 3L45Gp and 3L90Gp CLT panels were modelled for simulations of poor gluing. Two alternatives for modelling reduced contact surfaces were used. The most favourable way (with respect to retaining twisting stiffness) of reducing the surface was to remove the central part (named B in Fig. 3) of each contact surface and keep the contact condition on only the outer part of the surface (named A in Fig. 3). The most unfavourable way (with respect to twisting stiffness) was to remove the outer part

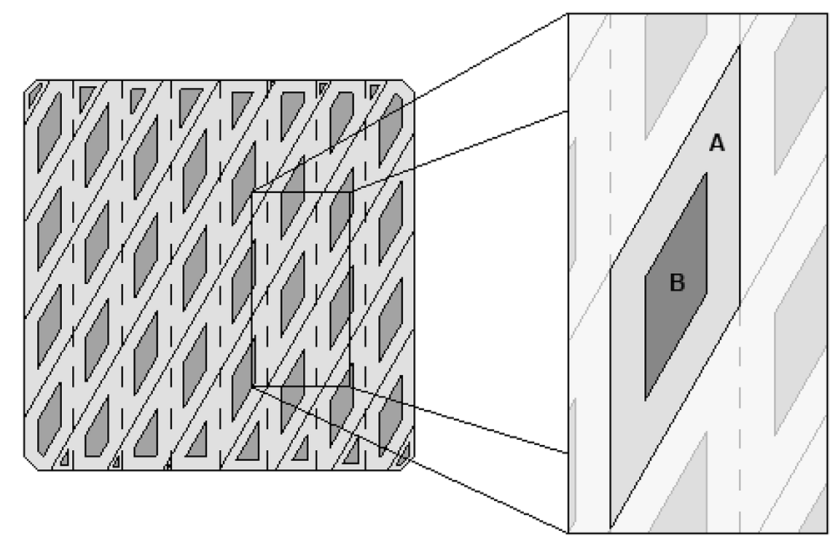

Fig. 3 The reduced contact surfaces for the models representing the 3L30Gp CLT panels

of the surface (named A in Fig. 3) and keep the contact conditions on the central surface (named B in Fig. 3). The glued area was measured for each tested CLT panel, and both favourable and unfavourable FE simulations were conducted. Models with both surfaces $A$ and $B$ glued were simulated for all CLT panels.

All FE simulated models are listed in Table 2. For the diagonal compression test simulations, models representing an ordinary CLT panel were simulated only in the crossfibre direction. The non-ordinary models were simulated in both the fibre and the cross-fibre directions. All diagonally compressed models were simulated with a global mesh size according to Table 2 and C3D20R cuboid elements in the commercial ABAQUS FE programme [17]. The relative linear displacements were measured as described earlier in Sect. 2.1.

\subsubsection{FE simulations of full-scale CLT walls in order to get $G$}

The problem of calculating $G$ for a CLT wall was addressed by comparing two kinds of FE simulations. At first, an FE model of the CLT wall in full-scale was created as previously described with the same board dimensions as presented in Table 1. The CLT wall was deformed by a surface traction force and the resulting mean shear displacement, $\Delta x$ as shown in Fig. 4, was noted. Then a model (with isotropic material properties) of the same CLT wall was modelled as a solid continuum with no boards. The isotropic wall model was created with the same outer dimensions and loaded with a surface traction force as the corresponding CLT wall model. An isotropic material model was chosen because CLT, in a general case, does not have a specific material direction. An isotropic material also made it easier to achieve $G$. The modulus of elasticity for the isotropic wall was set to $E_{l}$ (same as for the CLT wall). Then, the shear modulus of the isotropic wall was varied and adjusted to 
Table 2 Notations and properties of FE simulated models

\begin{tabular}{|c|c|c|c|c|c|c|c|c|}
\hline \multirow[t]{3}{*}{ Model } & & \multicolumn{2}{|l|}{ Side edge } & \multicolumn{2}{|c|}{ Glued surface } & \multicolumn{3}{|c|}{ Global mesh size $[\mathrm{mm}]$} \\
\hline & & \multirow[t]{2}{*}{ Gaps "Gp" } & \multirow[t]{2}{*}{ Glued "Eg" } & \multirow[t]{2}{*}{ A"Sa" } & \multirow[t]{2}{*}{$\mathrm{B} " \mathrm{Sb}^{\prime \prime}$} & \multirow[t]{2}{*}{$\begin{array}{l}\text { Diagonal com- } \\
\text { pression test }\end{array}$} & \multicolumn{2}{|c|}{$\begin{array}{l}\text { Full-scale CLT wall simula- } \\
\text { tion }\end{array}$} \\
\hline & & & & & & & CLT wall & Isotropic wall \\
\hline \multirow[t]{3}{*}{ To define Eq. (1) } & 3L30GpSab ${ }^{1}$ & $x$ & & $x$ & $x$ & 10.0 & $w_{\text {board }} / 5$ & $w_{\text {board }} / 5$ \\
\hline & 3L45GpSab ${ }^{1}$ & $x$ & & $x$ & $x$ & $"$ & $"$ & $"$ \\
\hline & 3L90EgSab ${ }^{2}$ & & $x$ & $x$ & $x$ & $"$ & $"$ & $"$ \\
\hline \multirow[t]{12}{*}{ To verify Eq. (1) } & $3 \mathrm{~L} 30 G p S a^{1}$ & $x$ & & $x$ & & $"$ & $"$ & $"$ \\
\hline & $3 \mathrm{~L}^{3} 0 \mathrm{GpSb}{ }^{1}$ & $x$ & & & $x$ & $"$ & $"$ & $"$ \\
\hline & $3 \mathrm{~L}_{45 \mathrm{GpSa}}{ }^{1}$ & $x$ & & $x$ & & $"$ & $"$ & $"$ \\
\hline & $3 \mathrm{~L}_{45 \mathrm{GpSb}}{ }^{1}$ & $x$ & & & $x$ & $"$ & $"$ & $"$ \\
\hline & $3 \mathrm{~L} 90 \mathrm{GpSa}{ }^{2}$ & $x$ & & $x$ & & $"$ & $"$ & $"$ \\
\hline & $3 \mathrm{~L} 90 \mathrm{GpSb}{ }^{2}$ & $x$ & & & $x$ & $"$ & $"$ & $"$ \\
\hline & 3L90GpSab² & $x$ & & $x$ & $x$ & $"$ & $"$ & $"$ \\
\hline & $3 \mathrm{~L} 90 \mathrm{Sab}^{2}$ & & & $x$ & $x$ & $"$ & $"$ & $"$ \\
\hline & $3 \mathrm{~L} 90 \mathrm{MSab}{ }^{2}$ & & & $x$ & $x$ & $"$ & $w_{\text {board }} / 2.5$ & $w_{\text {board }} / 6.3$ \\
\hline & 3L90MEgSab 2 & & $x$ & $x$ & $x$ & $"$ & $"$ & $"$ \\
\hline & 5LOMSab ${ }^{2}$ & & & $x$ & $x$ & $"$ & $w_{\text {board }} / 2.9$ & $w_{\text {board }} / 7.3$ \\
\hline & 5L0MEgSab ${ }^{2}$ & & $x$ & $x$ & $x$ & $"$ & " & " \\
\hline
\end{tabular}

${ }^{1}$ Model was simulated in the fibre and the cross-fibre directions

${ }^{2}$ Model was only simulated in the cross-fibre direction

Fig. 4 FE simulation of a full-scale CLT wall with the resulting mean shear displacement, $\Delta \mathrm{x}$. Arrows illustrate the surface traction force of $1 \mathrm{~N} /$ $\mathrm{mm}^{2}$ applied on the top of the wall. The dashed box shows the area where the $x$-displacements are less affected by the outer edges of the wall. The dash-dotted box illustrates the dashed box after deformation. Grey scale shows the main laminate directions [mm]

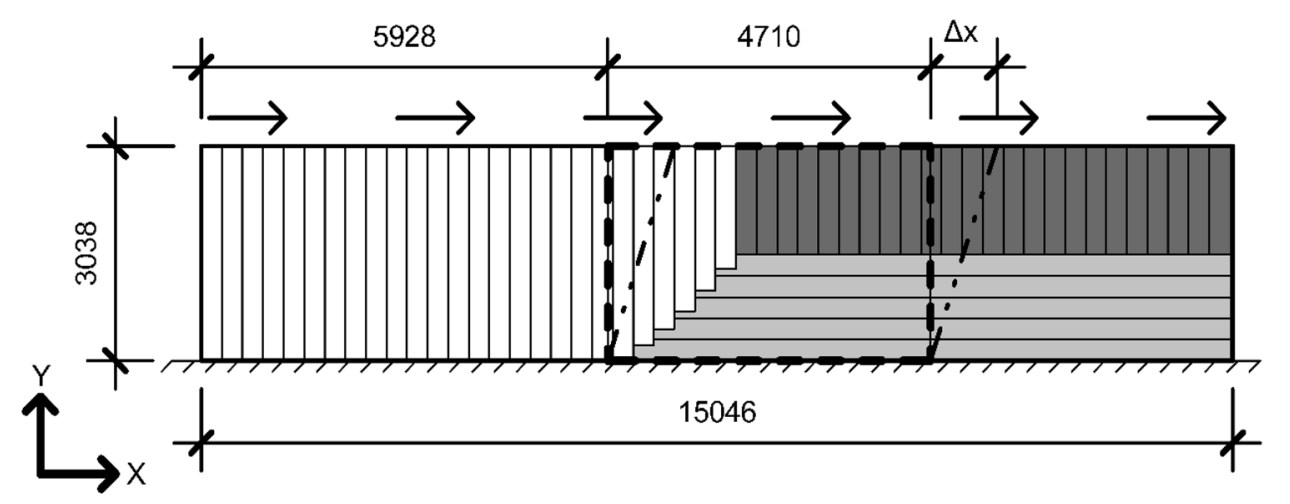

give the same $\Delta x$ as for the CLT wall model. The shear modulus obtained for the isotropic wall was assumed to be the $G$ value of the CLT wall. By using this method, $G$ values for all the CLT panels were calculated. By knowing the $G$ values, an equation for calculating $G$ in the diagonal compression test was obtained.

The dimensions of the CLT walls are shown in Fig. 4 for full-scale CLT wall models. The thickness of the CLT walls was based on the panel thickness. A surface traction force of $1 \mathrm{~N} / \mathrm{mm}^{2}$, illustrated with arrows in Fig. 4, was applied. The shear displacement, $\Delta x$, was measured in the $x$-direction as the mean displacement of the dashed box top surface illustrated in Fig. 4. This measured area was limited to get a displacement that was less affected by the right and left outer edges.
The main laminate direction of the odd layers for the ordinary and non-ordinary CLT panels was vertically directed in all CLT wall models, and for the non-ordinary panels, the main laminate direction of the mid layer was rotated in the clockwise direction. Due to limited computer power, different global mesh sizes were used for the CLT wall models. The global mesh size of the CLT wall and the isotropic wall models are shown in Table 2. All models were meshed with C3D20R cuboid elements.

A meshed deformation picture of the $3 \mathrm{~L} 45 \mathrm{GpSab}$ fullscale CLT wall simulation is presented in Fig. 5. 
Fig. $5 x$-direction deformation illustrated by the relative to the maximum displacement for the full-scale CLT wall simulation of $3 \mathrm{~L} 45 \mathrm{GpSab}$

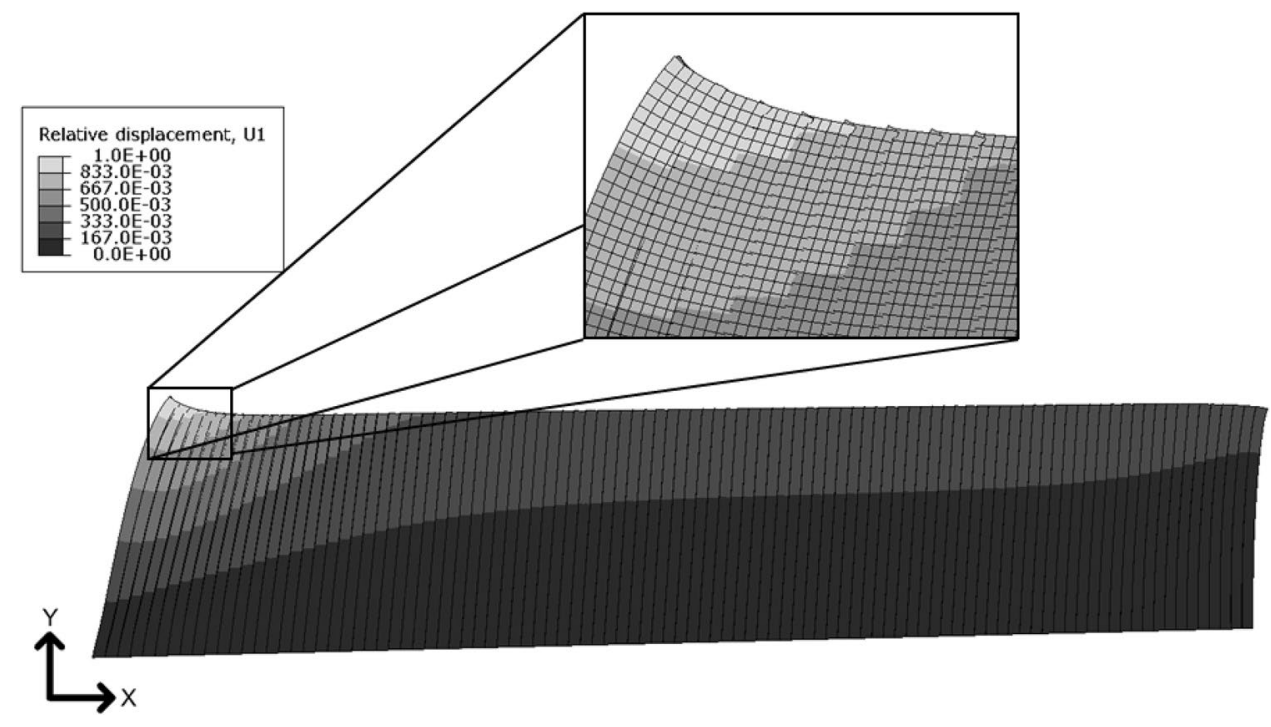

\subsubsection{Calculation of $G$ in the diagonal compression test}

An equation to calculate $G$ for the CLT panels tested in the diagonal compression test was created; see Eq. (1). The equation was defined by the force increment, $F_{\text {Inc }}$ for which the relative displacements $\Delta_{\text {active }}$ and $\Delta_{\text {passive }}$ were measured. This relationship between the $F_{l n c}$ and $\Delta_{\text {active }}$ or $\Delta_{\text {passive }}$ was called the shear stiffness. The length between the measuring points, the side length of the CLT panel and the thickness of the CLT panel were denoted $L_{M}, L_{T}$ and $t$, respectively. To get Eq. (1) size-independent, $L_{T}, L_{M}$ and $t$ were included in the equation. In the case of non-ordinary CLT panels, $\Delta_{\text {active }}$ and $\Delta_{\text {passive }}$ were calculated as the mean value from the compression of both the fibre and the cross-fibre directions. The equation was created based on EN 408 [18] using one adjustment factor, $a_{D}$, for each main laminate direction of the mid layer.

$G=\alpha_{D} \frac{L_{M}}{2 \sqrt{2} t L_{T}} \frac{F_{l n c}}{\left|\Delta_{\text {active }}\right|+\left|\Delta_{\text {passive }}\right|}[\mathrm{MPa}]$

This method of using EN 408 [18] for calculating the $G$ value of the CLT panels was used earlier by Brandner et al. [12] and Silly [19] for a similar test method. The models used to evaluate $a_{D}$ were 3 L30GpSab, $3 \mathrm{~L} 45 \mathrm{GpSab}$ and $3 \mathrm{~L} 90 \mathrm{EgSab}$, see Table 2 . The value of $a_{D}$ was calculated by using the $G$ value (from full-scale CLT wall simulation) and the shear stiffnesses (from diagonal compression test simulation) achieved for each $\mathrm{FE}$ simulated model. To check if there was any influence from $L_{M}$ or the support length, $L_{S}$, on $G$, four additional versions of $3 \mathrm{~L} 90 \mathrm{EgSab}$ were created. In two of them, the ratio $L_{S} / L_{T}$ was changed from 0.11 to 0.05 and 0.22 . In the other two, the ratio $L_{M} /\left(L_{T} \sqrt{2}\right)$ was changed from 0.61 to 0.30 and 0.90 .
A material-independent and dimensionless shear modulus, $G^{*}$, was calculated according to Eq. (2) in order to achieve a value suitable for comparisons between variants with different material properties. This value was calculated for all FE simulations.

$G^{*}=\frac{G}{G_{l r}}$

\subsection{Confirmation of the $G$ equation}

Eleven CLT panels were built and tested in order to check the validity of Eq. (1). The panels were built of Norway spruce boards (Picea abies) classified to C24 according to the Swedish standard SS-EN 338:2016 [15] The CLT panels were designed and built as 3L30Gp, 3L45Gp and 3L90Gp; see Tables 1 and 3 for dimensions and material properties. A standard polyvinyl acetate glue was used. The CLT panels were built by using less amount of glue than recommended by the glue manufacturer [20] in order to analyse the reduction of the glued areas effect on G. The CLT panels named 3L90M and 5LOM were built

Table 3 Material properties for the tested CLT panels with coefficient of variation (COV) within parentheses

\begin{tabular}{llll}
\hline Name & $\begin{array}{l}\text { No. of CLT } \\
\text { panels }\end{array}$ & $E_{l}[\mathrm{MPa}]$ & MC [\%] \\
\hline 3L30Gp & 3 & $11,685(18.0 \%)$ & 10.6 \\
3L45Gp & 4 & $"$ & $"$ \\
3L90Gp & $"$ & $"$ & $"$ \\
3L90M & $"$ & $9657(16.9 \%)$ & 9.9 \\
5L0M & 6 & $10,757(15.5 \%)$ & 8.7 \\
\hline
\end{tabular}




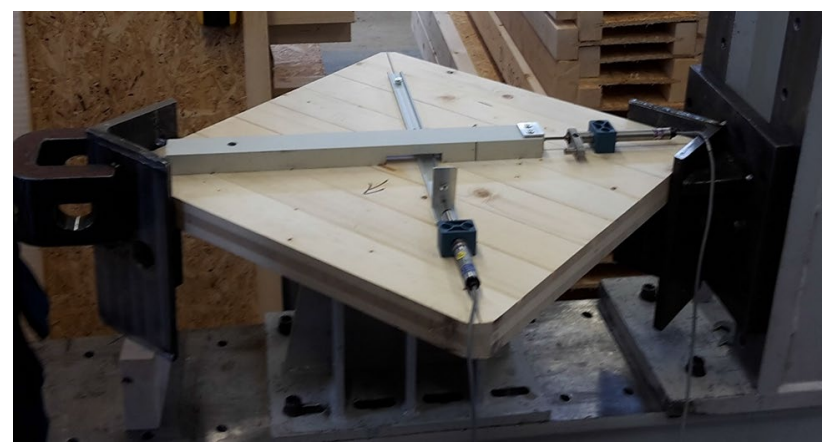

Fig. 6 A CLT panel during the diagonal compression test with attached displacement transducers

Table 4 Maximum loading force $F_{\text {max }}$ during the diagonal compression test in the cross-fibre direction and, within parentheses, in the fibre direction

\begin{tabular}{lll}
\hline Name & $F_{\text {max }}[\mathrm{N}]$ & Range $[\mathrm{N}]$ \\
\hline 3L30Gp & $4800(5500)$ & 4000 to 4800 \\
3L45Gp & $10,000(15,000)$ & 5000 to 10,000 \\
3L90Gp & 13,000 & $"$ \\
3L90M & 300,000 & 100,000 to 150,000 \\
5L0M & 350,000 & 200,000 to 300,000 \\
\hline
\end{tabular}

The loading range for measuring the linear displacements $\Delta_{\text {active }}$ and $\Delta_{\text {passive }}$. The same range was used independent of the loading direction

of Norway spruce boards (Picea abies) by a manufacturer as described in Table 1. These CLT panels were glued with polyurethane glue and without reduction. All tested CLT panels were built without glued side edges. A total of 374 clear wood samples was used to measure the mean modulus of elasticity in the fibre direction, $E_{1} E_{l}$ was measured by the four-point flexural test according to the Swedish standard SS-EN 408 [18]. The moisture content (MC) was measured by the oven-dry method. Material properties for the tested CLT panels are shown in Table 3.

\subsubsection{CLT panels in the diagonal compression test}

Tests were performed according to [6] where displacement transducers were used on the top side of the CLT panels, as shown in Fig. 6. Displacement transducers could not be used on the down side of the CLT panels due to the support for preventing downward bending. The displacement transducers were positioned according to the description presented earlier in Sect. 2.1.

The maximum force, $F_{\max }$ and the measuring range for the $\Delta_{\text {active }}$ and $\Delta_{\text {passive }}$ displacements are presented in Table 4. All non-ordinary CLT panels were tested in both the fibre and the cross-fibre directions. The $G$ value was calculated for all ordinary and non-ordinary CLT panels according to Eq. (1). No CLT panel was tested to rupture.

An Omegadyne LCHD-100 K and Vishay HS25 displacement transducers were used to measure the force and displacements, respectively. The accuracy of the force and displacement transducers were $200 \mathrm{~N}$ and $0.05 \mathrm{~mm}$, respectively.

\subsubsection{Reduction of the glue area}

The size of the glued areas was measured after the diagonal compression test on the 3 L30Gp, 3L45Gp and 3L90Gp CLT panels. The glue area percentage of the CLT panels was estimated by cutting out nine sample cubes (as shown in Fig. 7a) from each tested CLT panel. These sample cubes were separated in each glue line. A transparent grid sheet with a grid size of $10 \times 10 \mathrm{~mm}$ was used to estimate the area of the glued contact surface, as shown in Fig. 7b. Each sample cube had a size of $80 \times 80 \times 45 \mathrm{~mm}$.

The area of the grid was judged to be glued if a wooden failure was observed within the area. The glue area
Fig. 7 The position of the sample cubes in a CLT panel (a) and a transparent grid sheet on the glue surface of a separated sample cube to determine glue area percentage $(\mathbf{b})[\mathrm{mm}]$

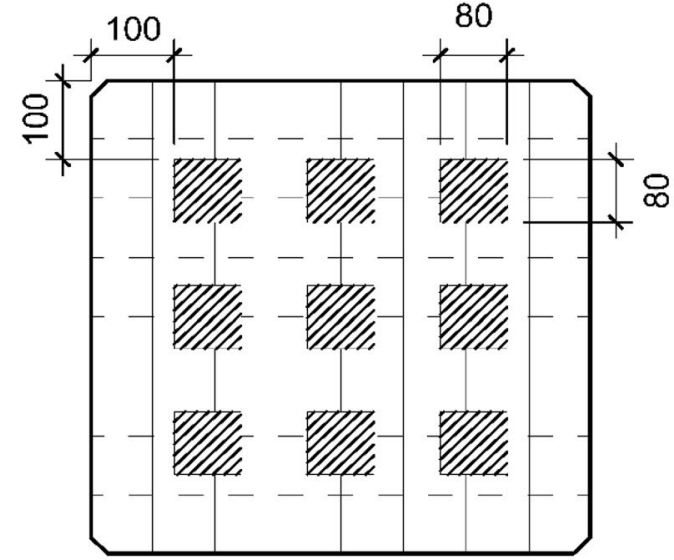

(a)

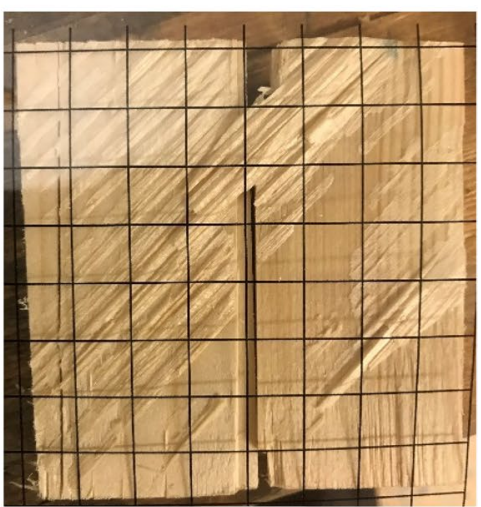

(b) 
percentage was estimated by calculating the ratio of the number of squares in the grid containing wood failure and the total number of squares covering the glue surface. Then, the mean glue area percentage was calculated for each group of the CLT panels.

\section{Result and discussion}

The mean glue area percentage for 3L30Gp, 3L45Gp and 3 L90Gp was measured to $51 \%, 47 \%$ and $59 \%$, respectively. The COV of the mean glue area percentage was $16.3 \%, 15.1 \%$ and $13.1 \%$ for 3 L30Gp, 3L45Gp and 3L90Gp, respectively.

The $a_{D}$ factor was calculated from FE simulations to 7.15 and 6.56 for the $30^{\circ}$ and $45^{\circ}$ main laminate direction of the mid layers, respectively. The $a_{D}$ factor for the ordinary CLT panels was calculated to 2.52 . By using the $a_{D}$, the $G$ values were calculated for the tested CLT panels; see Table 5. The highest $G$ value was calculated for $3 \mathrm{~L} 45 \mathrm{Gp}$, which also had a $G^{*}$ value over 1.0. This means that the $G$ value was higher than $G_{l r}$ in solid wood. This becomes possible because shearing of a CLT panel with non-uniform main laminate directions does not result in a pure shearing of the boards. The high $G^{*}$ values for $3 \mathrm{~L} 90 \mathrm{M}$ and $5 \mathrm{LOM}$ indicate that the side edges were partly glued. This was also confirmed by a visual inspection of the tested CLT panels.

The $G^{*}$ relative to $3 \mathrm{~L} 90 \mathrm{Gp}$ as a function of the mid layer main laminate direction is shown in Fig. 8 for 3 L30Gp, $3 L 45 \mathrm{Gp}$ and $3 \mathrm{~L} 90 \mathrm{Gp}$. An increase of $G^{*}$ with a factor of 2.9 (from 0.36 to 1.05 ) was achieved by a rotation of the mid layer from $90^{\circ}$ to $45^{\circ}$. An increase with a factor of 1.8 (from 0.36 to 0.65 ) was achieved by a rotation of the mid layer from $90^{\circ}$ to $30^{\circ}$.

\subsection{Evaluation of the shear modulus equation}

With use of the $a_{D}$ factor, the $G^{*}$ values were calculated for the diagonally compressed models and the full-scale CLT wall simulations; see Table 6 .

A reduction of $G^{*}$ was seen for all three tested laminate directions due to the reduction of the contact area with glue; see the Sab models compared to the Sa and Sb models for the main laminate direction in Table 6. All three

Table 5 Shear modulus, $G$, and material-independent and dimensionless shear modulus, $G^{*}$, for the tested CLT panels in the diagonal compression test, with coefficient of variation (COV) in parentheses

\section{SN Applied Sciences}

\begin{tabular}{lll}
\hline Name & G [MPa] & $G^{*}$ \\
\hline 3L30Gp & $480.0(9.3 \%)$ & 0.65 \\
3L45Gp & $771.4(2.2 \%)$ & 1.05 \\
3L90Gp & $265.6(12.1 \%)$ & 0.36 \\
3L90M & $550.7(7.3 \%)$ & 0.91 \\
5L0M & $612.6(15.6 \%)$ & 0.91 \\
\hline
\end{tabular}

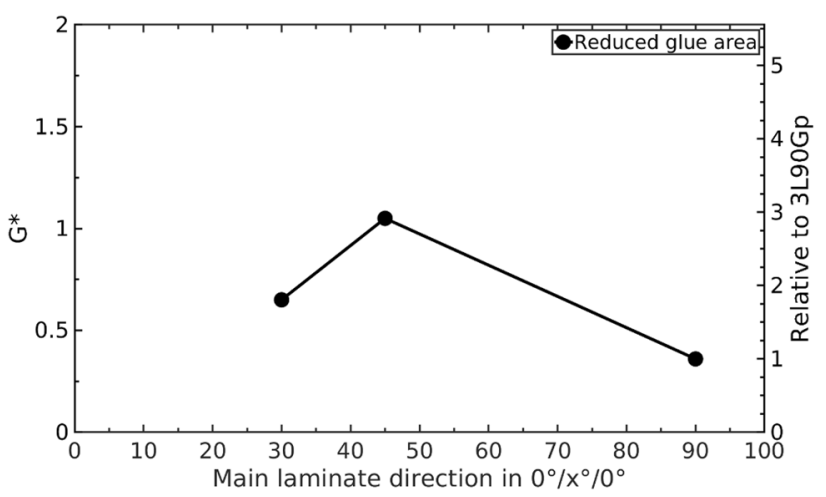

Fig. 8 Material-independent and dimensionless shear modulus, $G^{*}$, and relative to $3 \mathrm{~L} 90 \mathrm{Gp}$ as a function of the main laminate direction in the mid layer for the 3-layer CLT panels (3L30Gp, 3L45Gp and 3L90Gp) with reduced glue area

ranges between the $\mathrm{Sb}$ and Sa were large, and for $3 \mathrm{~L} 45 \mathrm{Gp}$ and 3 L90Gp presented in Table 5, the $G^{*}$ values were within this range. The CLT panels $3 \mathrm{~L} 30 \mathrm{GpSa}, 3 \mathrm{~L} 45 \mathrm{GpSa}$ and 3L90GpSa had a similar $G^{*}$ as 3L30GpSab, 3L45GpSab and 3L90GpSab, respectively. This showed that the pattern of the glue area between the layers was more important than the percentage of the glue area. The $G$ value calculated from the full-scale CLT wall simulations corresponded to $G_{l r}$ when the side edges were glued; see the $G^{*}$ value for 3L90EgSab, 3L90MEgSab and 5L0MEgSab in Table 6. This has been concluded earlier by Berg et al. [5].

The mean difference between the diagonal compression test simulations and the full-scale CLT wall simulations was $11.9 \%$. The largest difference was calculated for $3 \mathrm{~L} 45 \mathrm{GpSb}$ where Eq. (1) underestimated the $G$ value. This difference resulted due to the weaker cross-fibre direction measured in the diagonal compression test (see Fig. 2b). In the full-scale CLT wall simulation, the deformation as shown in Fig. 5 was more uniformly spread, independently of the contact area appearance. The same situation also occurred for $3 \mathrm{~L} 30 \mathrm{GpSb}$. The third largest difference between diagonal compression test simulations and the full-scale CLT wall simulations was for model 5LOMSab. This reduction was due to the few boards per layer which built the CLT panel. The $G^{*}$ values of the tested CLT panels $3 \mathrm{~L} 90 \mathrm{M}$ and $5 \mathrm{LOM}$ presented in Table 5 were within the range of non-edge glued and edge glued; see the $G^{*}$ values for the diagonal compression test simulation in Table 6. This was also visually confirmed on the tested CLT panels that the side edges were partly glued.

Based on the board dimensions, the $G^{*}$ value for 3 L90Sab was estimated to 0.72 by Turesson et al. [4]. This value was close to and between the two $G^{*}$ values from the diagonal compression test simulation and the full-scale CLT wall simulation; see 3L90Sab in Table 6. The same value of $G^{*}$ as 3 L90Sab was estimated by Turesson 
Table 6 Material-independent and dimensionless shear modulus, $G^{*}$, from the diagonal compression test and the full-scale CLT wall simulation to verify Eq. (1)

\begin{tabular}{llllc}
\hline & Model & $\begin{array}{l}G^{*} \text { from diagonal com- } \\
\text { pression simulation }\end{array}$ & $\begin{array}{l}G^{*} \text { from full-scale CLT } \\
\text { wall simulation }\end{array}$ & Difference \\
\hline To define Eq. (1) & 3L30GpSab & 1.40 & 1.40 & $0 \%$ \\
& 3L45GpSab & 1.78 & 1.77 & $0 \%$ \\
& 3L90EgSab & 1.0 & 1.0 & $0 \%$ \\
To verify Eq. (1) & 3L30GpSb & 0.66 & 1.07 & $38.3 \%$ \\
& 3L30GpSa & 1.36 & 1.33 & $2.3 \%$ \\
& 3L45GpSb & 0.74 & 1.39 & $46.8 \%$ \\
& 3L45GpSa & 1.75 & 1.71 & $2.3 \%$ \\
& 3L90GpSb & 0.33 & 0.32 & $3.1 \%$ \\
& 3L90GpSa & 0.63 & 0.69 & $8.7 \%$ \\
& 3L90GpSab & 0.65 & 0.69 & $5.8 \%$ \\
& 3L90Sab & 0.71 & 0.75 & $5.3 \%$ \\
& 3L90MSab & 0.76 & 0.73 & $4.1 \%$ \\
& 3L90MEgSab & 1.08 & 1.0 & $8.0 \%$ \\
& 5LOMSab & 0.66 & 0.79 & $16.5 \%$ \\
5LOMEgSab & 1.01 & 1.0 & $1.0 \%$ \\
\hline
\end{tabular}

The absolute difference was calculated between the $G^{*}$ values from the diagonal compression test and the full-scale CLT wall analysis et al. [4] for 3L90GpSab but with neglected board gap. In this case, the calculated $G^{*}$ values in the diagonal compression test simulation and the full-scale CLT wall simulation were lower than 0.72 due to the gaps between the boards. This reduction due to the gaps between boards was described earlier by Turesson et al. [4] and Moosbrugger et al. [21].

By using external data from another practical diagonal compression test [6], $G^{*}$ resulted in 0.81 and 0.93 for the group of CLT panels named 3-layer $R$ and 5 -layer $R$, respectively. These values of $G^{*}$ were estimated to 0.8 and 0.85 , respectively, by Turesson et al. [4]. This shows that Eq. (1) with the $a_{D}$ factor set to 2.52 correctly calculated $G$ for the 3-layer R panels ( $G^{*}$ calculated to 0.81 and estimated by Turesson et al. [4] to 0.8) but was overestimated for the 5 -layer $\mathrm{R}$ panels ( $G^{*}$ calculated to 0.93 and estimated by Turesson et al. [4] to 0.85 ). In the study by Turesson et al. [6], it is commented that the 5 -layer $\mathrm{R}$ panels may have been partly edge glued. This would result in higher measured shear stiffnesses and then a too high calculated $G$.

Sensitivities of Eq. (1) from the side length of the CLT panel, $L_{T}$, the distance between measuring points, $L_{M}$, and the support length, $L_{S}$, are shown in Table 7. The $G$ value is presented as the dimensionless shear modulus $G^{*}$ in Table 7. Both ratios $L_{M} /\left(L_{T} \sqrt{2}\right)$ and $L_{S} / L_{T}$ influenced on $G$. There was a negligible sensitivity for a $L_{M} /\left(L_{T} \sqrt{ } 2\right)$ ratio between 0.30 to 0.61 . Higher ratios of $L_{M} /\left(L_{T} \sqrt{2}\right)$ were negatively correlated to $G$. A linear negative correlation between $L_{S} / L_{T}$ ratio and $G$ was detected. The change, expressed in $G^{*}$, was linear and -0.03 per 0.06 change of $L_{S} / L_{T}$ ratio.
Table 7 Sensitivity of Eq. (1) shown as the material-independent and dimensionless shear modulus $G^{*}$

\begin{tabular}{lll}
\hline Parameter & Parameter value & $G^{*}$ \\
\hline$L_{M} /\left(L_{T} \sqrt{ } 2\right)$ & 0.30 & 0.99 \\
& $\mathbf{0 . 6 1}$ & $\mathbf{1 . 0 0}$ \\
& 0.90 & 0.93 \\
$L_{S} / L_{T}$ & 0.05 & 1.03 \\
& $\mathbf{0 . 1 1}$ & $\mathbf{1 . 0 0}$ \\
& 0.22 & 0.94 \\
\hline
\end{tabular}

Bold values are for the reference case 3L90EgSab

The $G^{*}$ relative to $3 L 90 G p S a b$ as a function of the mid layer main laminate direction from full-scale CLT wall simulation is shown in Fig. 9 for 3L30GpSab, 3L45GpSab and 3 L90GpSab. An increase of $G^{*}$ with a factor of 2.6 (from 0.69 to 1.77 ) was achieved by a rotation of the mid layer from $90^{\circ}$ to $45^{\circ}$. An increase with a factor of 2.0 (from 0.69 to 1.40 ) was achieved by a rotation of the mid layer from $90^{\circ}$ to $30^{\circ}$. These increases (2.6 and 2.0) were similar to the increases achieved for the tested CLT panels with reduced glue area (2.9 and 1.8), as shown in Fig. 8. In the study by Bosl [7], a lower increase (2 compared to 2.6) was seen. One difference between this study and that of Bosl was the proportion of layers with a $45^{\circ}$ main laminate direction. Bosl used CLT panels, where the $45^{\circ}$ mid layer corresponded to $1 / 5$ of the CLT panel thickness. In this study, the ratio was $1 / 3$. Due to the higher proportion of layers with a $45^{\circ}$ main laminate direction, a larger increase of $G$ was seen. Another reason 


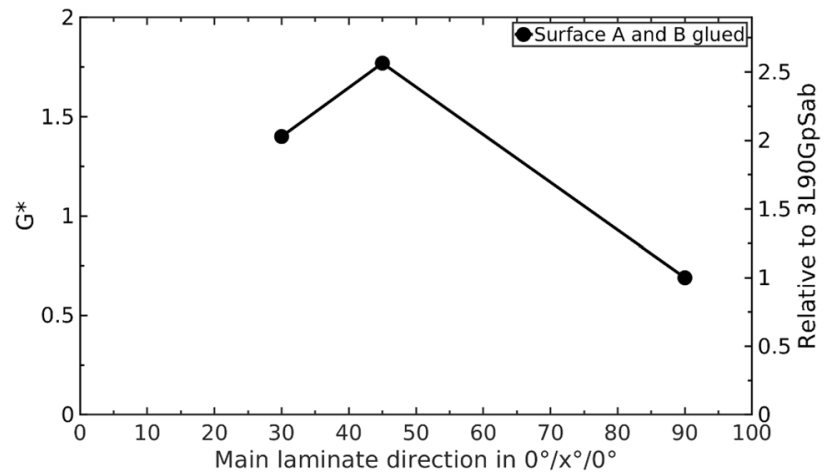

Fig. 9 Material-independent and dimensionless shear modulus, $G^{*}$, and relative to $3 \mathrm{~L} 30 \mathrm{GpSab}$ as a function of the main laminate direction in mid layer for 3-layer CLT panels (3L30GpSab, 3L45GpSab and 3L90GpSab models)

could also be that this study took the advantage of testing both diagonal directions of the CLT panel.

\section{Conclusion}

An equation (Eq. (1)) was established to calculate the shear modulus, $G$, for CLT panels. The equation was based on the shear stiffness from a diagonal compression test and a factor derived from finite element simulations.

By using the equation, the effect of reduced glue area between the layers was calculated. The results showed that the pattern of the glue area was more important than the size of the glue area. It was possible to make a large reduction of the glue area with almost no effect on $G$ if the remaining glue area was located on the periphery. However, the reduction of $G$ was large if the remaining glue area was in the middle.

The effect on $G$ by varying the main laminate direction of the mid layer for a 3-layer CLT panel was also calculated. This means using the main laminate directions $0^{\circ}, 30^{\circ}$ and $0^{\circ}$ and $0^{\circ}, 45^{\circ}$ and $0^{\circ}$ (non-ordinary) instead of the traditional $0^{\circ}, 90^{\circ}$ and $0^{\circ}$ (ordinary) directions. An increase of $G$ for a finite element simulated CLT panel with a factor of 2.0 and 2.6 was achieved by rotating the mid layer to $30^{\circ}$ and $45^{\circ}$, respectively. These factors were also measured to 1.8 and 2.9 on tested CLT panels. This large increase of $G$ was due to the "bracing" effect of using the mid layer orientations $\left(30^{\circ}\right.$ and $\left.45^{\circ}\right)$ arranged in the same direction as a traditional bracing. This means that by using non-ordinary main laminate directions, it is possible to increase $G$ of CLT walls. Compared to ordinary CLT, non-ordinary CLT would, by less material, lead to a stiffer construction, which can be beneficial for tall buildings.
Acknowledgements The conducted work was financed by the European Union Interreg Nord programme in a project called "Future CLT". Cooperation between two Swedish partners and three Finnish partners took place. The authors are grateful for their support.

Funding Open access funding provided by Lulea University of Technology.

\section{Compliance with ethical standards}

Conflict of interest On behalf of all authors, the corresponding author states that there is no conflict of interest.

Open Access This article is licensed under a Creative Commons Attribution 4.0 International License, which permits use, sharing, adaptation, distribution and reproduction in any medium or format, as long as you give appropriate credit to the original author(s) and the source, provide a link to the Creative Commons licence, and indicate if changes were made. The images or other third party material in this article are included in the article's Creative Commons licence, unless indicated otherwise in a credit line to the material. If material is not included in the article's Creative Commons licence and your intended use is not permitted by statutory regulation or exceeds the permitted use, you will need to obtain permission directly from the copyright holder. To view a copy of this licence, visit http://creativecommons .org/licenses/by/4.0/.

\section{References}

1. Lukacs I, Björnfot A, Tomasi R (2019) Strength and stiffness of cross-laminated timber (CLT) shear walls: State-of-the-art of analytical approaches. Eng Struct 178(1):136-147. https://doi. org/10.1016/j.engstruct.2018.05.126

2. Brandner R, Flatscher G, Ringhofer A, Schickhofer G, Thiel A (2016) Cross laminated timber (CLT) overview and development. Eur J Wood Wood Prod 74(3):331-351. https://doi.org/10.1007/ s00107-015-0999-5

3. Reynolds T, Casagrande D, Tomasi R (2016) Comparison of multistorey cross-laminated timber and timber frame buildings by in situ modal analysis. Constr Build Mater 102:1009-1017. https ://doi.org/10.1016/j.conbuildmat.2015.09.056

4. Turesson J, Berg S, Ekevad M (2019) Impact of board width on in-plane shear stiffness of cross-laminated timber. Eng Struct 196:109249. https://doi.org/10.1016/j.engstruct.2019.05.090

5. Berg S, Turesson J, Ekevad M, Björnfot A (2019) In-plane shear modulus of cross-laminated timber by diagonal compression test. Bioresour 14(3):5559-5572. https://doi.org/10.15376/biore s.14.3.5559-5572

6. Turesson J, Björnfot A, Berg S, Ekevad M, Tomasi R (2019) Picture frame and diagonal compression testing of cross-laminated timber. Mater Struct 52:66. https://doi.org/10.1617/s1152 7-019-1372-7

7. Bosl R (2002) Zum Nachweis des Trag- und Verformungsverhaltens von Wandscheiben aus Brettlagenholz. Military University Munich, Munich (in German)

8. Björnfot A, Boggian F, Steinsvik Nygård A, Tomasi R (2017) Strengthening of traditional buildings with slim panels of crosslaminated timber (CLT). In: Proceedings of the 4th International Conference on Structural Health Assessment of Timber Structures (SHATIS'17), Istanbul, 20-22 September. 
9. Bogensperger T, Moosbrugger T, Schickhofer G (2007) New test configuration for CLT-wall-elements under shear load. In: Proceedings of International council for research and innovation in building and construction, working commission W18-Timber structures (CIB-W18/40-21-2), Bled, 28-31 August.

10. Dujic B, Klobcar S, Zarnic R (2007) Influence of openings on shear capacity of wooden walls. In: Proceedings of International council for research and innovation in building and construction, working commission W18-Timber structures (CIB-W18/4015-6), Bled, 28-31 August.

11. Andreolli M, Rigamonti MA, Tomasi R (2014) Diagonal compression test on cross laminated timber panels. In: Proceedings of the 13th world conference on timber engineering (WCTE 2014), Quebec, 10-14 August.

12. Brandner R, Dietsch $P$, Dröscher J, Schulte-Wrede $M$, Kreuzinger $\mathrm{H}$, Sieder M (2017) Cross laminated timber (CLT) diaphragms under shear: test configuration, properties and design. Constr Build Mater 147:312-327. https://doi.org/10.1016/j.conbuildma t.2017.04.153

13. Kreuzinger $H$, Sieder $M$ (2013) Einfaches Prufverfahren zur Bewertung der Schubfestigkeit von Kreuzlagenholz/Brettsperrholz. Bautech 90(5):314-316. https://doi.org/10.1002/bate.20130 0024 (in German)

14. ASTM (2015) ASTM E519/E519M-15 Standard test method for diagonal tension (shear) in masonry assemblages. ASTM International, West Conshohocken, PA. https://doi.org/10.1520/ E0519_E0519M-15

15. SIS (2016) Swedish Standard SS-EN 338:2016 Structural timberStrength classes. Swedish Institute for Standards, Stockholm
16. SIS (2004) Swedish Standard SS-EN 1995-2:2004 Eurocode 5: Design of timber structures-Part 2: Bridges. Swedish Institute for Standards, Stockholm

17. Simulia Abaqus 6.14-4, Abaqus/CAE User's Guide

18. SIS (2012) Swedish Standard SS-EN 408:2010+A1:2012 Timber structures-Structural timber and glued laminated timberDetermination of some physical and mechanical properties. Swedish Institute for Standards, Stockholm

19. Silly G (2014) Schubfestigkeit der BSP-Scheibe-numerische Untersuchung einer Prüfkonfiguration. Research report, holz. bau forschungs gmbh, Graz University of Technology, Graz (in German)

20. Cascol Trälim Indoor 3301, 3304 Association promotion information [2017-12-04]. https://media-pms2.schoenox.net/casco /docs/cascocascolindoor_se_se_tds.pdf

21. Moosbrugger T, Guggenberger W, Bogensperger T (2006) Crosslaminated timber wall segments under homogeneous shear: with and without openings. In: Proceedings of the 9th world conference on timber engineering (WCTE 2006), Portland, 6-10 August.

Publisher's Note Springer Nature remains neutral with regard to jurisdictional claims in published maps and institutional affiliations. 